\title{
Architectural constraints, male fertility variation and biased floral morph ratios in tristylous populations
}

\author{
Nicolay Leme da Cunha $\mathbb{1}^{1,2} \cdot$ Spencer C. H. Barrett $\mathbb{1}^{3}$ \\ Received: 13 April 2019 / Revised: 13 May 2019 / Accepted: 14 May 2019 / Published online: 29 May 2019 \\ (c) The Genetics Society 2019
}

\begin{abstract}
Tristyly is a genetic polymorphism in which populations are comprised of three floral morphs (mating types) differing reciprocally in sex-organ height. Intermorph (disassortative) mating governed by a trimorphic incompatibility system should result in 1:1:1 morph ratios at equilibrium, but both deterministic and stochastic processes can cause skewed morph ratios in tristylous populations. Here, we investigate mechanisms causing morph-ratio bias in Pontederia parviflora, an emergent aquatic native to tropical America. We compared reproductive traits among morphs and surveyed 71 populations to determine patterns of morph-ratio bias. We then used simulation models of morph-frequency dynamics to test the hypothesis that morph-specific differences in pollen production and their influence on male fertility can explain patterns of morph-ratio bias. Ninety-seven percent of populations that we sampled were tristylous, but with a significant excess of the short-styled morph and a deficiency of the long-styled morph. Atypically for a tristylous species, mid-level anthers of the short-styled morph produced over twice as much pollen compared with the corresponding anthers of the long-styled morph. Our computer models incorporating this difference in male fertility resulted in morph ratios not significantly different from the average frequencies from our survey suggesting that the short-styled morph is more successful than the long-styled morph in siring ovules of the mid-styled morph. We propose that the difference in male fertility between morphs may be a nonadaptive consequence of a developmental constraint caused by the architecture of tristyly in Pontederiaceae.
\end{abstract}

\section{Introduction}

In plant species with sexual polymorphisms, mating is nonrandom because populations are reproductively sub-divided into distinct mating groups that are only able to mate with compatible partners. The maintenance of sexual polymorphisms is governed by negative frequency-dependent

Supplementary information The online version of this article (https:// doi.org/10.1038/s41437-019-0237-8) contains supplementary material, which is available to authorized users.

Nicolay Leme da Cunha

nicolaycunha@gmail.com

1 Programa de Pós-Graduação em Ecologia e Conservação, Universidade Federal de Mato Grosso do Sul, Campo Grande, Mato Grosso do Sul 79070-900, Brazil

2 Grupo de Ecología de la Polinización, INIBIOMA, CONICETUniversidad Nacional del Comahue, Quintral 1250, Rio Negro, San Carlos de Bariloche 8400, Argentina

3 Department of Ecology and Evolutionary Biology, University of Toronto, 25 Willcocks Street, Toronto, Ontario M5S 3B2, Canada selection, in which the ability of a mating type to successfully reproduce depends, in part, on the frequency of compatible sexual morphs (Clarke et al. 1988; Eckert et al. 1996; McCauley and Brock 1998; Barrett et al. 2004). Frequencydependent selection can lead to various ratios of the mating types in populations, depending on whether they are equally suitable partners or not. In either case all mating types should realize equivalent fitness at equilibrium. One of the classic examples in plants of a sexual polymorphism maintained by negative frequency-dependent selection is heterostyly.

Populations of heterostylous plants are comprised of two (distyly) or three (tristyly) floral morphs (mating types) that differ reciprocally in anther and stigma height (Darwin 1877; Barrett 1993; Lloyd and Webb 1992). In most heterostylous species, floral polymorphism is associated with a heteromorphic incompatibility system that prevents selfand intramorph mating. Compatible pollinations only occur between stigmas and anthers at the same height resulting in intermorph (disassortative) mating. In addition to reciprocal herkogamy and heteromorphic incompatibility, the floral morphs of heterostylous species also differ in a suite of ancillary polymorphisms including differences in stigma 


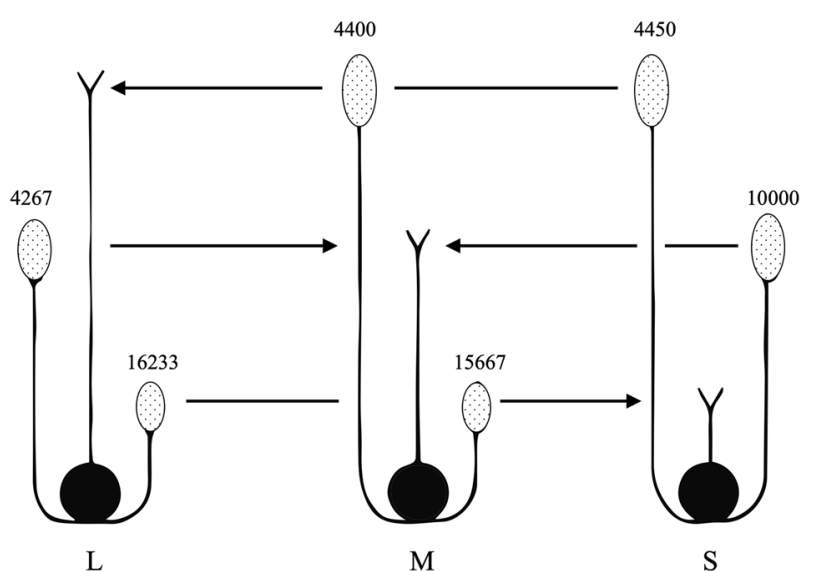

Fig. 1 The arrangement of sex organs (styles and stamens) in the floral morphs of tristylous Pontederia parviflora. L, M, S refer to the long-, mid, and short-styled morphs and arrows are the compatible pollinations. Mean pollen production values for each stamen level are indicated based on our measurements. Note the large difference in pollen production between mid-levels anthers of the L- and S-morphs

characters, pollen size and pollen production (Dulberger 1992). Heterostylous floral polymorphisms are reported from 28 angiosperm families and have multiple independent origins providing outstanding examples of convergence in floral form and function.

Populations of tristylous species are typically comprised of long-, mid- and short-styled morphs (hereafter L-, M-, Smorphs, Fig. 1). Studies on the genetics of tristyly indicate that the most common form of inheritance involves two diallelic loci $(S, M)$ with the $S$ locus epistatic to the $M$ locus (Fisher and Mather 1943; Eckert and Barrett 1993; Weller 1976a, 1976b, Gettys and Wofford 2008). Plants with a dominant $S$-allele are S-morph (SsMM, SsMm, Ssmm) and those that are homozygous recessive at the $S$-locus are either M-morph if they carry a dominant $M$-allele (ssMM, ss $M m$ ), or L-morph (ssmm) if they are homozygous recessive at both loci (Lewis and Jones 1992). Fisher undertook the first theoretical analysis of equilibrium morph ratios in tristylous populations (Fisher 1941). He demonstrated that 1:1:1 morph ratios (isoplethy) could be maintained from generation to generation by negative frequency-dependent mating. Subsequently, Heuch (1979a) formulated a general theorem for tristylous populations and showed that, provided that there are no fitness differences among the morphs, isoplethy was the only possible equilibrium in large populations with disassortative mating. However, empirical studies of deviations from isoplethy and the underlying causes responsible for morph-ratio biases in tristylous populations are relatively scarce.

Theoretical models have been valuable in identifying potential factors causing morph-ratio bias and morph loss from tristylous populations (Charlesworth 1979; Barrett et al. 1989; Eckert and Barrett 1992; Weber et al. 2013b). A variety of deterministic (Heuch 1979b; Barrett et al. 1983;
2004; Ågren and Ericson 1996) and stochastic processes (Heuch 1980; Husband and Barrett 1992; Eckert and Barrett 1995) have the potential to cause uneven morph ratios (anisoplethy) in tristylous populations (reviewed in Barrett 1993). Despite the phenotypic equilibrium of equal morph ratios resulting from disassortative mating, the frequency of alleles at the two loci controlling tristyly differ markedly because of dominance and epistasis (Fisher 1941; Heuch and Lie 1985). As a consequence, the pattern of inheritance of tristyly plays an important role in causing morph-ratio bias and morph loss in finite populations because of genetic drift and founder events (Heuch 1980; Morgan and Barrett 1988; Husband and Barrett 1992; Eckert and Barrett 1992; Balogh and Barrett 2016). The tristylous sexual polymorphism therefore provides an unusual opportunity for examining the relative importance of stochastic processes and negative frequency-dependent selection in governing phenotypic evolution in plant populations.

Here, we examine floral morph ratios in Pontederia parviflora (Pontederiaceae) an aquatic macrophyte of tropical wetland environments. This species has previously been reported from Panama as homostylous, with populations comprised of a single self-pollinating floral form with long-level anthers and stigmas at a similar position within a flower (Fig. 3 in Lowden 1973). However, our preliminary observations in the Pantanal wetlands of Brazil indicated that plants were polymorphic for style length, with welldeveloped herkogamy. This discovery motivated the present study. We first determined whether populations were tristylous and compared reproductive traits among the morphs. This comparison confirmed the occurrence of tristyly but also revealed a striking difference in pollen production between mid-level anthers of the L- and S-morph, a pattern atypical for most tristylous species but previously reported in two other Pontederia species (Price and Barrett 1982; Glover and Barrett 1983). Differences in male fertility among the floral morphs of tristylous species are potentially capable of causing biased morph ratios (Barrett et al. 1983; Hodgins and Barrett 2008; Weber et al. 2013a) thus motivating us to investigate morph frequencies in relation to morph-specific pollen production in a large sample of population of $P$. parviflora.

Our study addresses the following specific questions: (1) Are populations of $P$. parviflora characterized by $1: 1: 1$ morph ratios, and if not are particular patterns of morphratio bias evident? This was achieved by sampling morph ratios in 71 populations across a wide area of the Pantanal wetlands in central Brazil encompassing diverse habitat types and flooding regimes. The survey revealed a consistent pattern of morph-ratio bias inconsistent with signatures predicted by stochastic models and suggesting that deterministic processes may play a role in causing bias. (2) Can morph-specific differences in pollen production explain 
the observed pattern of morph-ratio bias? We investigated this hypothesis by using deterministic and stochastic models of morph-frequency dynamics in finite tristylous populations (e.g., Barrett et al. 1983; Heuch and Lie 1985; Morgan and Barrett 1988). Our models included differences among morphs in male fertility based on morph-specific pollen production data and are extensions of those presented in earlier studies of biased morph ratios in the related Pontederia cordata (Barrett et al. 1983; Morgan and Barrett 1988). The morph ratios resulting from our models were remarkably congruent with the observed morph ratios.

\section{Materials and methods}

\section{Study species}

Pontederia parviflora is an emergent freshwater perennial aquatic occurring in marshlands, drainage ditches and on the margins of sandy streams and ponds, often under saline conditions (Fig. S1). Plants grow to $2 \mathrm{~m}$ in height and form clumps up to two meters in diameter bearing inflorescences with numerous densely packed white, tristylous, 'one-day', uniovulate flowers (Fig. 2a, b). Anthesis ranges from 6 to $8 \mathrm{~h}$ depending on temperature and inflorescences bloom for four to six days. The species is recorded from Panama, Colombia, Venezuela and Brazil and is especially abundant in the Pantanal wetlands of Brazil, where our studies were conducted (Lowden 1973; Pott and Pott 2000).

Population in $P$. parviflora vary greatly in size and plants often occur at high density forming extensive monospecific stands (Fig. 2c). Vegetative propagation occurs by lateral expansion of the rhizome. In the Pantanal wetlands, populations of $P$. parviflora can be observed flowering yearround in permanent ponds, although peak flowering is from October to March (wet season). There is no published information on the pollination biology of $P$. parviflora; however, in the Pantanal we commonly observed longtongued solitary bees, butterflies and day-flying Sphingid moths visiting flowers for nectar. After flowering, geniculation (downward bending) of the inflorescence results in seed maturation close to or below the water surface (Fig. $2 \mathrm{~b}$ ), and seeds mature in $\sim 20-30$ days after pollination depending on temperature. Once seeds are shed from infructescences they float and can be dispersed by water currents in streams and during flooding, and also by birds.

\section{Comparison of reproductive traits among floral morphs}

Our preliminary observations in the Pantanal indicated the occurrence of three morphs in P. parviflora. To determine

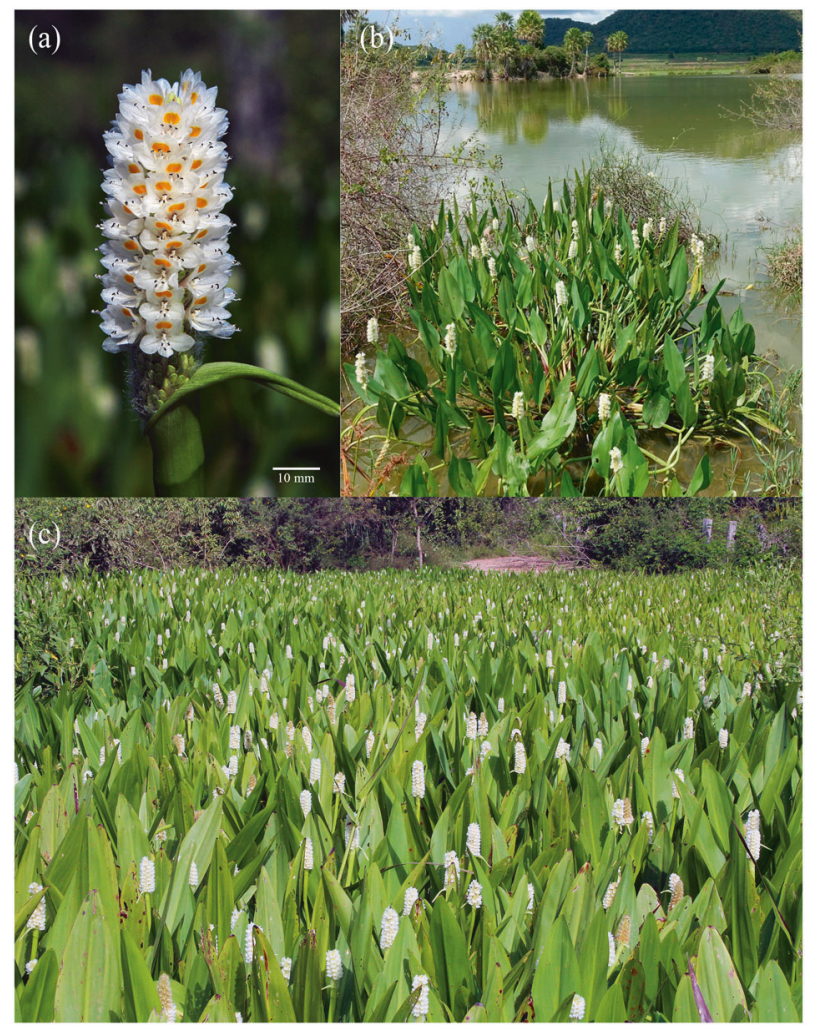

Fig. 2 Tristylous Pontederia parviflora in the Pantanal of Brazil. (a) inflorescence, (b) individual plant, (c) monospecific mass-flowering population

whether populations were indeed tristylous and to provide quantitative data on reproductive traits, we sampled five populations in two distinct regions of the Pantanal in 2016 (Table S1, Fig. S2). In each population, we haphazardly collected a single inflorescence and infructescence from 15 individuals of each style morph, separated by at least $5 \mathrm{~m}$ ( $n=225$ plants). In the field, we measured flower length, petal width, floral tube width and the width of the base of the floral tube, from a single randomly chosen flower per inflorescence using digital callipers $( \pm 0.1 \mathrm{~mm})$. Detailed information on flower measurements and landmarks used can be found in Figure S1 of Cunha et al. (2014). To investigate sex-organ size and position among morphs, we measured the style length and anther height of all six stamens, taking measurements from the base of the ovary. To compare flower production among morphs we counted all buds, opened flowers and senesced flowers on sampled inflorescences. To compare seed production among morphs, we counted all developing fruits and aborted flowers on harvested infructescences. Finally, to estimate pollen size and production among morphs and anther levels, we sampled buds from sampled inflorescences and stored them in plastic micro-centrifuge tubes with $70 \%$ ethanol. In the laboratory, we measured pollen grain size and estimated 
pollen production following methods described by Cunha et al. (2014).

\section{Floral morph frequencies in populations}

To investigate morph-frequency variation in $P$. parviflora (Table S1) we sampled a total of 71 populations in five regions of the Pantanal (Fig. S2). After confirming the existence of three style length classes by measuring floral traits in five populations, our subsequent identification of the floral morphs in the field was straightforward and could be done by simple observation. For smaller populations with $\sim 150$ flowering individuals or fewer, we recorded the floral morph of all plants. In larger populations, we sampled plants at intervals of $>2 \mathrm{~m}$ along transects separated by $\sim 3 \mathrm{~m}$ from each other, as has been used in previous studies of floral morph sampling in heterostylous taxa (e.g., Cunha et al. 2014). Pontederia parviflora, exhibits the 'phalanx clonal growth strategy' (see Vallejo-Marín et al. 2010, Fig. 2 ), in which all ramets are physically connected. Although we cannot guarantee that our sampling approach completely eliminates repeated sampling of the same genet, it is unlikely to introduce any systematic bias to the morph frequency data. We visually estimated population size by counting the number of flowering ramets in each population. We made a special effort to sample populations in full bloom and avoided sampling populations at the beginning or end of the flowering season.

\section{Statistical analysis}

\section{Flower size}

To examine whether the five populations of $P$. parviflora differed in flower size among the floral morphs we first reduced the dimensionality of the four perianth measurements using principal component analysis (PCA). We used the Kaiser-Guttman criteria (variance higher than 1) to determine the number of axes representing floral size and shape. As PC1 and PC2 satisfied the criteria, we calculated distinct general mixed models with Gaussian distribution for each axis. The scores of each PC were then used as dependent variables and morph as a fixed effects, and population as a random effect in the model.

\section{Reciprocal herkogamy}

To examine whether the five populations of $P$. parviflora exhibited reciprocity between stigma and anther heights of the morphs, the principle criterion establishing a species as heterostylous, we used general linear mixed models, with the length of sex-organs as the dependent variable, and the type of sex organ [long- $(l)$, mid- $(m)$ and short-level $(s)$ anthers, and Long- (L), Mid- (M) and Short- (S) styles] as a single fixed effect with six levels, and individuals nested within population as random effects. Thus, three measurements were made for each individual (e.g., L-morph: Lstyle, $m$ - and $s$-stamens). If populations were tristylous we would expect to find no substantial differences in length between $l$-anthers and L-styles, $m$-anthers and M-styles and $s$-anthers and S-styles, whereas all other combinations would be statistically different.

\section{Flower and seed production}

To investigate variation in flower and seed number per inflorescence among the morphs in the five populations sampled, we used generalized mixed models with a negative binomial distribution. We avoided using a Poisson distribution because of over-dispersion and convergence problems within the models. We used the total flower number per inflorescence (sum of buds, open flowers and senesced flowers per inflorescence) as the dependent variable, and morph as a fixed effect and population as a random effect. For seed number, we used the total seeds produced per inflorescence as the dependent variable, and morph as a fixed effect and population as a random effect.

\section{Pollen size and production}

To compare pollen size among morphs and anther levels, we used pollen size as the dependent variable, anther-level nested within style morph as a fixed effect, and the five populations as a random effect in a general linear mixed model. Lastly, we used pollen production as dependent variable, and anther-level nested within morph as a fixed effect and population as random effect in a generalized linear mixed model with a Poisson distribution.

\section{Floral morph frequencies}

We calculated the mean and overall frequency for each morph sampled in the 71 populations of $P$. parviflora. We tested for deviations from the expected 1:1:1 isoplethic equilibrium morph ratio for each population and the total pooled data using chi-square (Sokal and Rohlf 2011), and we assessed the significance of each test by simulating the $P$-value with 1000 randomizations. We tested for statistical differences in morph frequencies, using generalized linear mixed models (GLMM) with binomial errors weighted by the absolute number of individuals sampled in each population, with morph as a fixed effect and population as a random effect.

To investigate the relation between floral morph evenness and population size, we calculated the evenness index 
(E) described in Barrett et al. (1989), as follow:

$E=1-\frac{f(\mathrm{~L})^{2}+f(\mathrm{M})^{2}+f(\mathrm{~S})^{2}}{0.667}$

Where $f(\mathrm{X})=$ frequency of style morph-X $(\mathrm{L}=\mathrm{L}$-morph, $\mathrm{M}=\mathrm{M}$-morph, $\mathrm{S}=\mathrm{S}$-morph). The index ranges from 0 (monomorphic populations) to 1 (trimorphic population with 1:1:1 ratios). We then used the index values as dependent variables and the natural logarithm of population size as predictor variables in a generalized linear model with a gamma distribution.

To investigate if different patterns of bias in morph frequency were associated with population size, we classified populations into three size classes based on the estimated size in the field: 1-100, 101-500, and 501-maximum number of individuals per population (Table S1). We then compared the frequency of each morph among size classes using one-way ANOVA. Further, we used the same analysis to test for differences among morph frequencies within each size class. We determined significance among categories via Tukey post-hoc tests.

We tested all mixed models with random slopes and intercepts and determined significance using the Likelihood Ratio Test (LRT) and calculated posteriori pairwise comparisons with Tukey specific contrasts for significant models (Hothorn et al. 2008). We used R for all analysis and graphics (R Core Team 2017) with the packages "reshape" and "plyr" (Wickham 2007) for data manipulation, "multcomp" (Hothorn et al. 2008) for specific contrasts, "ggplot2" (Wickham 2009), "lattice" (Sarkar 2008) and "vcd" (Meyer et al. 2016) for graphics, "Ime4" (Bates et al. 2015) for general and generalized mixed models.

\section{Simulations of floral morph frequencies under different male fertilities}

To investigate whether differences in siring ability through male function owing to differences in pollen production among morphs may play a role in causing observed patterns of morph bias revealed by our survey we used analytical equations detailed in Barrett et al. (1983). To parameterize the model, we used as input the overall mean values for pollen production for each anther-level of $P$. parviflora and compared the predicted morph frequency with the observed frequency found among the 71 sampled populations. The equations used were:

$$
\begin{aligned}
& \mathrm{L}=\left(2+R_{m}\right)^{-1} \\
& \mathrm{M}=1-\left(2+R_{m}\right)^{-1}-R_{m}\left(1+2 R_{m}\right)^{-1} \\
& \mathrm{~S}=R_{m}\left(1+2 R_{m}\right)^{-1}
\end{aligned}
$$

where $\mathrm{L}, \mathrm{M}$, and $\mathrm{S}$ are the frequencies of the morphs and $R_{m}$ is the ratio between the pollen production of the $m$-anthers of the S- and L-morphs. The analytical solutions for these equations give identical results for a range of inheritance mechanisms for tristyly. For further details see appendix 2 of Barrett et al. (1983).

We investigated the importance of male fertility differences among morphs using both deterministic and stochastic simulations modified from Morgan and Barrett (1988) for examining the role of historical factors (e.g., founder events) on morph frequencies. In these analyses, we assumed complete disassortative mating, as species of Pontederia exhibit trimorphic incompatibility (Ornduff 1966; Glover and Barrett 1983; Puentes et al. 2013), and equal female fertility among morphs, as we also observed (see Results). We also assumed that the $S$ and $M$ loci were unlinked, as is the case in Pontederia (Gettys and Wofford 2008). For differential male fertility $(M)$, we used as parameter values the observed average estimates of pollen production for $P$. parviflora presented in the Results section. We iterated a single population of fixed size for 50 generations, which was enough to reach stable morph frequencies. We replicated the iteration 1000 times and followed the average trajectory of each floral morph. We initiated the iterations with populations of 100, 500 and 1000 individuals with the initial genotype composition a random sample from a population at approximate isoplethic equilibrium (genotype frequencies of: $s s m m=0.3333$, $s s M m=0.3094, s s M M=0.0239$, Ssmm $=0.122, S s M m=$ $0.122, S s M M=0.044$; following Heuch and Lie 1985). We explored visually the mean trajectory after each generation for all types of iteration with different and equal male fertility and compared the resulting values with the observed data for $P$. parviflora. We conducted the simulations in $\mathrm{R}$ using the package "Tristyly" (Morgan 2016).

\section{Results}

\section{Reproductive traits and sex-organ reciprocity}

Measurements of sex-organ height demonstrated that the five populations that we investigated were tristylous (Fig. 3). Our larger sample of populations confirmed this pattern as all but two populations sampled were comprised of three floral morphs differing reciprocally in stigma and anther height (Table S1). The first and second principal components of the distance matrix of flower measurements recovered 39 and $27 \%$ of the variation, respectively. PC1 was positively correlated with flower length $(r=0.66)$, petal width ( $r=0.72$ ) and floral-tube width $(0.75)$, and PC2 was only associated with the width of the base of the floral tube $(r=0.93)$. There was no significant difference in flower 


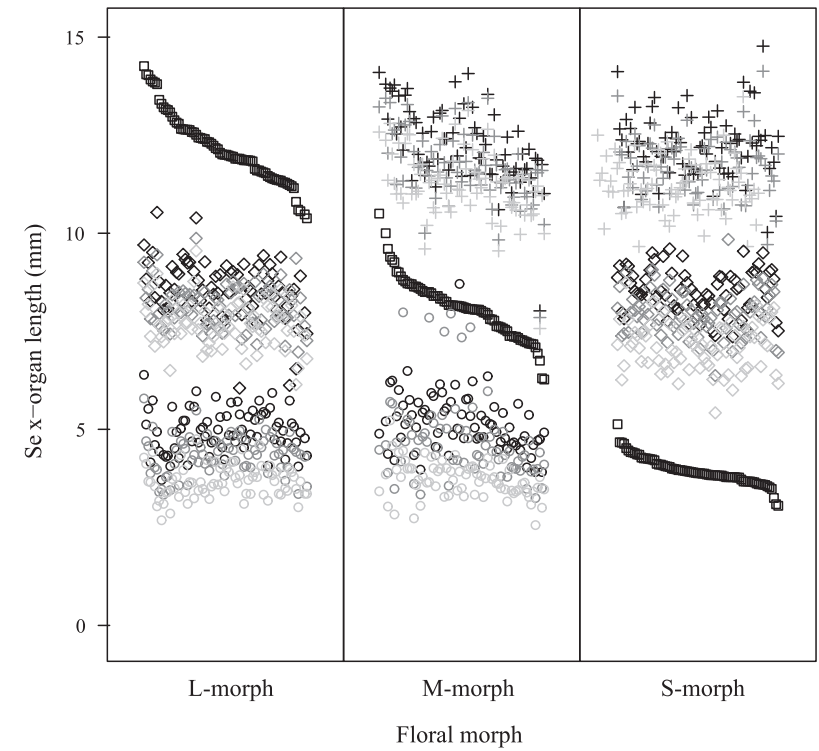

Fig. 3 Variation in stigma and anther height among floral morphs of $P$. parviflora from five populations in the Pantanal. Squares indicate stigma height, plus signs, diamonds and circles indicate the heights of the $l-, m$-, and $s$-level anthers, respectively. Colour gradients within anther height levels represent each of the three anthers per level. Note that within each floral morph individual flowers are ranked from left to right by style length

traits among morphs (GLMM, PC1, $\chi^{2}=2.46, \mathrm{df}=2, \mathrm{P}=$ 0.29 ; PC2, $\chi^{2}=0.61, \mathrm{df}=2, P=0.74$, Table S2). Similarly, there was no difference in height between $s$-anthers and $S$-styles (estimate $=0.38 \mathrm{~mm}$, standard error - s.e. $=$ $0.13, P=0.053$ ) and $m$-anthers and M-styles (estimate $=$ $0.05 \mathrm{~mm}$, s.e. $=0.20, P=1.00$ ), but stigmas of the L-morph were slightly higher than $l$-anthers (estimate $=0.45 \mathrm{~mm}$, s. e. $=0.13, P=0.01$ ). All other pairwise comparisons were highly statistically significant (Table S3), and showed estimated effects that were an order of magnitude greater than the comparisons between styles and anthers of the same height class (e.g., S-style vs $m$-anther, estimate $=-4.20$; M-style vs $s$-anther, estimate $=3.77$; Table S3), thus corroborating the tristylous syndrome in $P$. parviflora. There were no significant differences in total flower production per inflorescence (GLMM, $\chi^{2}=1.39$, df $=2, P=0.497$; Table S3) or seed production per infructescence (GLMM, $\chi^{2}=3.88, \mathrm{df}=2, P=0.143$; Table S4) among morphs.

As commonly found in tristylous species, the mean size of pollen grains was positively related to anther height (GLMM, $\chi^{2}=912$, df $=44, P<0.0005$, Fig. 4). Pairwise comparisons indicated that pollen grains from the same anther height but different style morph were not significantly different in size, but pollen grains of different anther heights were significantly different in size $(P<0.05$, Table S5). The grand mean pollen size $(\mu \mathrm{m})$ and standard error of the long-level anthers of the $\mathrm{M}$ - and S-morph were $49.95 \pm 0.74$ and $49.71 \pm 0.62$, respectively; for mid-level anthers of the L- and S morph: $42.43 \pm 0.47$ and $34.17 \pm$ 0.78; and for the short-level anthers of the L- and M-morph $=23.46 \pm 0.39$ and $24.69 \pm 0.52$, Table S6. In contrast, pollen production was inversely proportional to anther height (GLMM, $\chi^{2}=22.3, \mathrm{df}=5, P<0.0005$, Fig. $4 \mathrm{~b}$, Table S6). Mean pollen production was equivalent between $l$-anthers of the M- (mean \pm s.e., $4400 \pm 366.70$ ) and S-morphs $(4450 \pm 406.90)$, and $s$-anthers from L$(16233 \pm 776)$ and M-morphs $(15667 \pm 680)$. However, the $m$-anthers of the L-morphs produced significantly less pollen $(4267 \pm 338)$ than $m$-anthers of the S-morph $(10000 \pm$ 447.70) (Table S7, Fig. 4).

\section{Variation in style morph frequencies}

We identified the style morph of 13,251 flowering ramets among the 71 populations of $P$. parviflora sampled in the Pantanal. The mean number of ramets sampled per population was 186.6 (s.e. \pm 18.34 ; median 163). Estimated population sizes ranged from 4 to $40000(2343 \pm 644.7$; median 500). The overall frequency (summing all inflorescences sampled in the 71 populations) of the three morphs revealed a significant excess of the S-morph and a deficiency of the L-morph in comparison with the isoplethic prediction $\left(\mathrm{L}=0.266, \mathrm{M}=0.325, \mathrm{~S}=0.409 ; \chi^{2}\right.$ total $=420$, d.f. $=2, P<0.0005$; Table 1, Fig. 5). The mean frequency $( \pm$ s.e.) across all 71 populations gave essentially equivalent results: $\quad$ L-morph $=0.259 \quad( \pm 0.001), \quad$ M-morph $=0.333$ $( \pm 0.011)$ S-morph $=0.407 \quad( \pm 0.011)$. This pattern of Smorph bias was evident in four of the five geographical regions of the Pantanal, with one region (A) with only a small excess of the S-morph, probably because of the limited sample from this region (Table S8).

There was significant heterogeneity in morph frequencies among populations $\left(\chi^{2}\right.$ het $=310$, d.f. $\left.=140, P<0.0005\right)$ and about half of the 71 populations were anisoplethic $(52.11 \%$, $n=37, P<0.05$, Fig. 5, Table S1). The generalized linear model indicated that there were significant differences in morph frequency among populations (GLMM, $\chi^{2}=151$, d.f. $=2, P<0.0005$ ), with the S-morph most frequent, followed by the M- and L-morph (Tukey contrasts, S-L, estimate $=0.635, \quad P<0.0001 ; \quad \mathrm{S}-\mathrm{M}, \quad$ estimate $=0.353$, $P<0.0001 ; \mathrm{M}-\mathrm{L}$, estimate $=0.281, P<0.001)$. The index of morph evenness (E) ranged from 0.195 to 1.0, with a mean of $0.949( \pm 0.012$, median of 0.979$)$. There was a positive correlation between morph evenness and the logarithm of population size (estimate $=-0.025$, s.e. $=0.007 ; t$ value $=-3.65 ;$ pseudo- $R^{2}=0.09 ; \quad P<0.0005, \quad$ Fig. 6) . However, the general pattern of an excess of the S-morph and a deficiency of the L-morph was also evident across all population sizes (Table 1), and this was significant following ANOVA for all three size classes (class 1-100: $F_{2,51}=7.21, P<0.01$; class $101-500 ; F_{2,51}=18.52$, 
Fig. 4 Kernel density distribution of pollen size (left column) and pollen number (right column) among floral morphs of Pontederia parviflora in the Pantanal. Vertical dashed lines are grand means per anther level. Note the significantly higher pollen production in $m$-level anthers of the S-morph compared to the $m$-level anthers of the L-morph
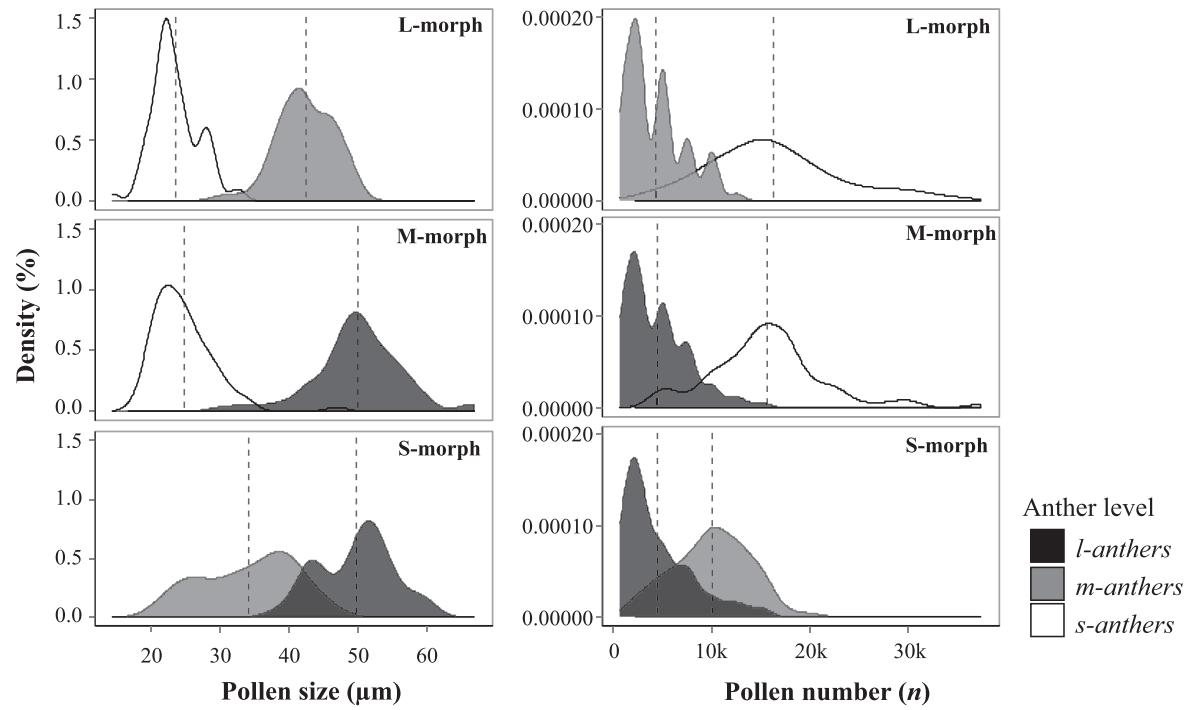

Table 1 Average frequency and standard error of floral morph frequencies in three population size classes and for the total sample of 71 populations of tristylous Pontederia parvifora

\begin{tabular}{|c|c|c|c|c|c|c|c|}
\hline \multirow{2}{*}{$\begin{array}{l}\text { Population } \\
\text { size class }\end{array}$} & \multirow[t]{2}{*}{$N$} & \multicolumn{2}{|l|}{ Long } & \multicolumn{2}{|l|}{ Mid } & \multicolumn{2}{|l|}{ Short } \\
\hline & & mean & s.e. & mean & s.e. & mean & s.e. \\
\hline $1-100$ & 18 & 0.2272 & 0.030 & 0.3517 & 0.0386 & 0.4211 & 0.0401 \\
\hline $100-500$ & 18 & 0.2633 & 0.011 & 0.3589 & 0.0139 & 0.3783 & 0.0171 \\
\hline 500-max & 35 & 0.2731 & 0.007 & 0.3109 & 0.0061 & 0.4154 & 0.0059 \\
\hline Total & 71 & 0.2590 & 0.001 & 0.3330 & 0.0110 & 0.4070 & 0.0110 \\
\hline
\end{tabular}

$P<0.001$; class 501-max $\left.F_{2,51}=129.9, P<0.001\right)$. There was no evidence that a particular morph was more frequent within any population class size (L-morph, $F_{2}, 68=2.28$, $P>0.05 ;$ M-morph, $F_{2}, 68=2.15, P>0.05 ;$ S-morph, $\left.F_{2,68}=1.13, P>0.32\right)$.

\section{Simulations of floral morph ratios with variation in male fertility}

Our simulations of disassortative mating among morphs gave strikingly different results depending on whether differences in pollen production at mid-level anthers of the L- and S-morph of $P$. parviflora were included in the model (Table 2, Fig. 7). With similar pollen production among equivalent anther heights, morph ratios reached the predicted equilibrium of 1:1:1 morph ratios. In contrast, when the observed difference in pollen production at midlevel anthers was included in the model the equilibrium ratio was not significantly different from the observed ratio (analytical solution: $\mathrm{L}$-morph $=0.23, \mathrm{M}$-morph $=0.36$ and $\mathrm{S}$-morph $=0.41$; observed mean morph ratio: $\mathrm{L}$-morph $=$ 0.26 , M-morph $=0.33$, S-morph $=0.41, \chi^{2}=0.004$, d.f. $=$ 2, $P<0.99$ ). Small differences in morph ratios were observed between the deterministic and stochastic

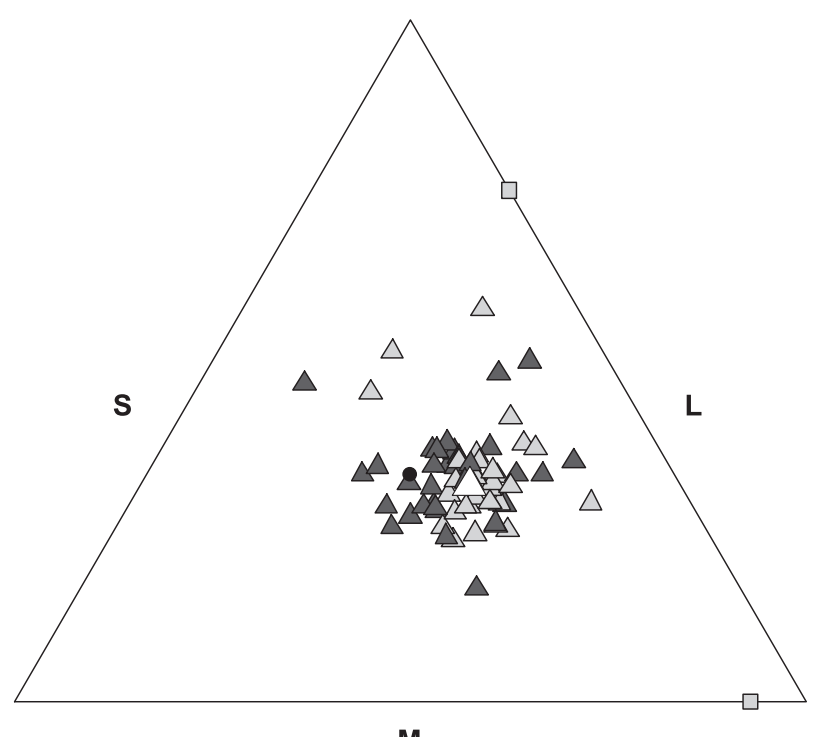

Fig. 5 De Finnetti diagram of floral morph frequencies in 71 populations of Pontederia parviflora sampled in the Pantanal wetlands. Trimorphic (three floral morphs) and dimorphic (two floral morphs) populations are represented as triangles and squares, respectively. The theoretical isoplethic equilibrium is indicated by the black filled circle. Dark gray triangles correspond to isoplethic populations $(n=34)$ and light gray triangles and squares to anisoplethic populations $(n=37)$, based on Chi-square tests (see Materials and Methods). The white filled triangle is the overall frequency based on all inflorescences counted in all populations

simulations with differential male fertility; nonetheless, the pattern obtained was always the same; the S-morph was most frequent and the $\mathrm{L}$-morph least frequent in populations.

\section{Discussion}

Disassortative mating resulting in negative frequencydependent selection should drive morph ratios in tristylous 


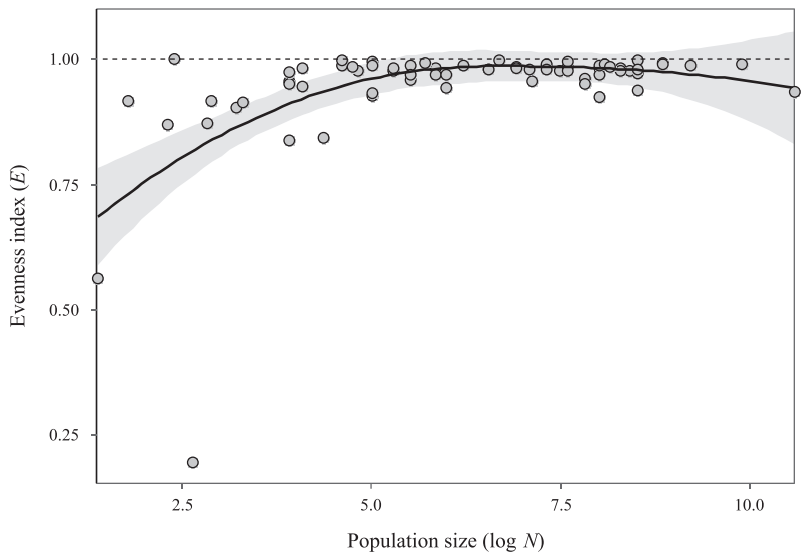

Fig. 6 Positive relation between morph evenness $(E)$ and the natural logarithm of population size among 71 populations of Pontederia parviflora in the Pantanal wetlands. The line was fitted using locally weighted scatterplot smoothing (LOESS) and the shaded area corresponds to the standard error estimate

populations to an isoplethic equilibrium of equal morph ratios (Fisher 1941; Heuch 1979a). But a range of stochastic and deterministic processes can cause biased morph ratios and morph loss from tristylous populations. Our investigation of $P$. parviflora revealed a consistent overrepresentation of the S-morph in populations. As argued below, this pattern of morph-ratio bias is unlikely to have arisen by stochastic processes alone but instead is more likely to be the result of morph-specific differences in male fertility. We now detail hypotheses and evidence for biased morph ratios in tristylous populations, consider the proximate morphological and developmental basis of the observed differences in pollen production among morphs of $P$. parviflora, and discuss the general implications of our findings for mating patterns in plant populations.

\section{Biased morph ratios in tristylous populations}

The most predictable departure from isoplethy in tristylous populations is loss of the S-morph owing to genetic drift and founder events (Heuch 1980; Barrett 1993). The signature of stochastic S-morph loss is particularly evident in tristylous species that frequently experience bottlenecks and episodes of small population size (e.g., Eichhornia paniculata - Husband and Barrett 1992; Lythrum salicaria Balogh and Barrett 2016). Our results from P. parviflora revealed no evidence of widespread morph loss as only two of 71 populations sampled were dimorphic for floral morph. Moreover, there was an excess of the S-morph in populations, a pattern not predicted by the genetic drift hypothesis. The abundance of $P$. parviflora in the Pantanal wetlands and frequent seed dispersal by water and birds, and pollen dispersal by pollinators, probably serves to maintain tristyly in most populations.

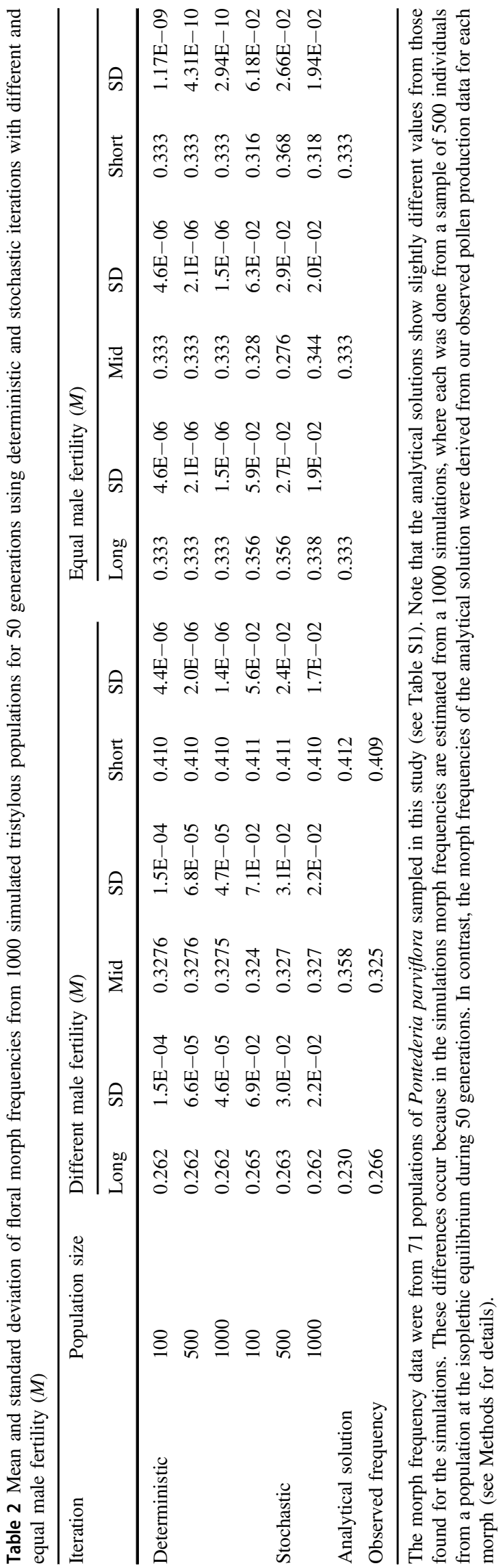


Fig. 7 The mean trajectory of floral-morph variation during 50 generations under deterministic and stochastic iterations with (a, b) equal and (c, d) differential male fertility among morphs, based on data for Pontederia parviflora. The mean trajectory was obtained from 1 000 simulated populations and the initial genotype composition of each population was a sample of 100,500 , and 1000 individuals of an isoplethic population. Here, we portray the results for a population of 500

plants only, the observed median population size for the

71 sampled populations in this study. Results for 100 and 1000 individuals gave the same overall patterns. Light gray, gray and dark gray denote the L-, Mand S-morph, respectively, and the shaded areas are the standard deviation of the mean
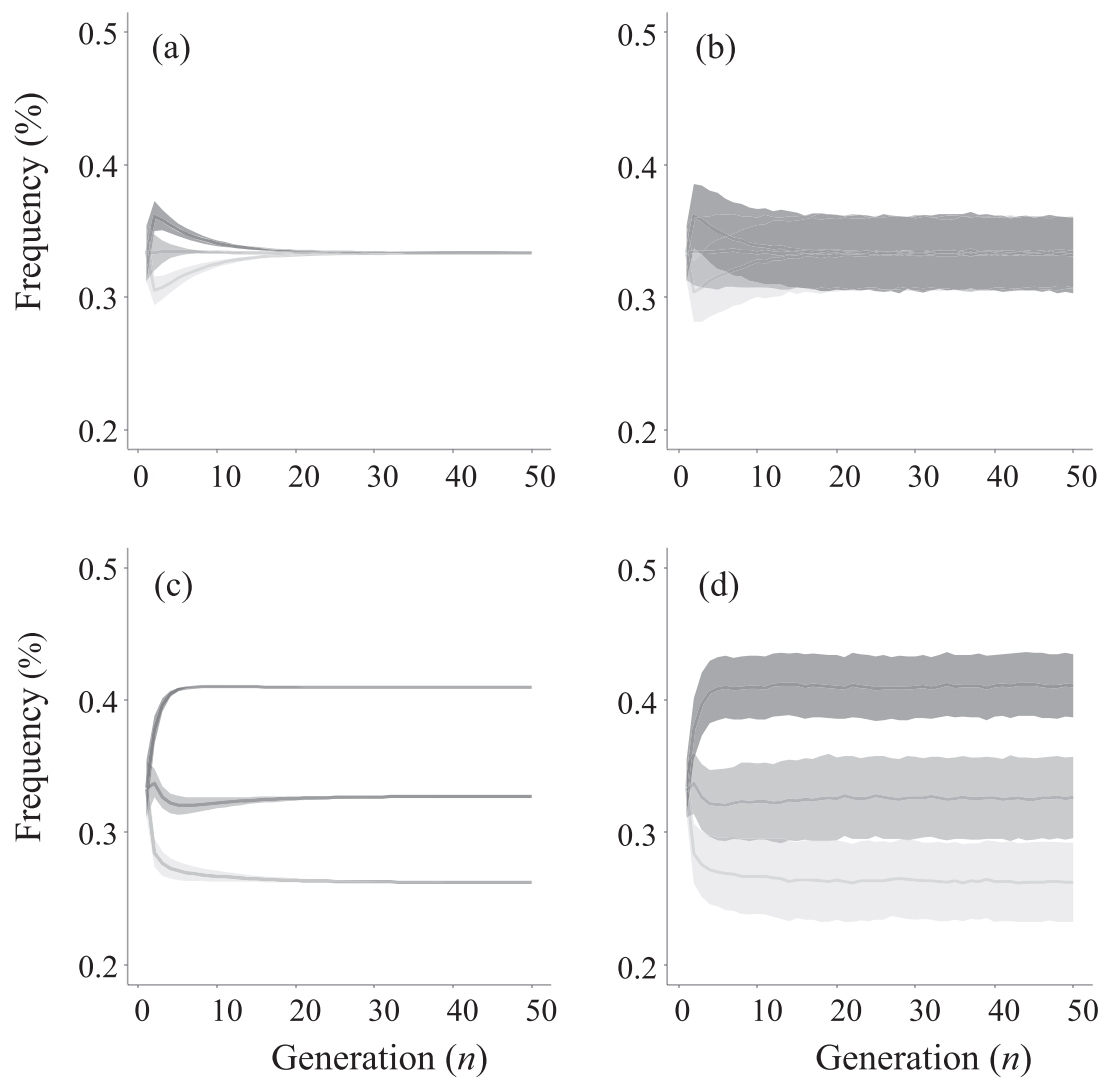

Historical contingency associated with the particular style-length genotypes that initiate populations can also cause biased morph ratios, sometimes over extensive areas. The limited representation of the M-morph in northern populations of Decodon verticillatus in eastern N. America (Eckert and Barrett 1995), predominance of the S-morph in introduced populations of Oxalis pes-caprae (Ferrero et al. 2015), and absence of the S-morph from the introduced range of Eichhornia crassipes (Barrett 1977a) provide good examples of the influence of founder events on geographical patterns of morph-frequency variation. At a local scale, a model of non-equilibrium morph frequencies in tristylous populations revealed biases determined by the genotypes of founding individuals, when phenotypic equilibrium is reached asymptotically (Morgan and Barrett 1988). These authors found an excess of the S-morph and a deficiency of the L-morph in early generations when populations were founded by the complete range of genotype combinations under the two-locus model of the inheritance of tristyly. Their results raise the question of whether such historical processes might explain the pattern of morph-ratio bias revealed by our survey. We cannot discount that some of the populations that we surveyed were in a non-equilibrium state, particularly those that were small and in which there was a higher variance in morph evenness (Fig. 6). However, we found a similar pattern of morph bias across the entire range of populations sizes, including many that were very large and more likely to be in an equilibrium state (Table 1, Table S1). This finding suggests that stochastic processes alone are unlikely to account for the consistent pattern of morph bias that we observed, especially in medium- to large-sized populations.

Theoretical models incorporating specific features of the reproductive system of tristylous species have provided insights on the role of deterministic processes causing biased morph ratios. A variety of life-history and reproductive traits can potentially contribute towards biased morph ratios, including clonal propagation following founder events (Eckert and Barrett 1992; Ferrero et al. 2015), inbreeding depression owing to partial expression of trimorphic incompatibility causing self-fertilization (Charlesworth 1979; Heuch 1979b; Weber et al. 2013b), morphspecific differences in assortative mating (Barrett et al. 2004) and male fertility (Barrett et al. 1983). The latter study on male fertility variation is most relevant to our findings because it involves a congener that shares several features with $P$. parviflora including biased morph ratios.

An extensive survey of morph frequencies in $P$. cordata in eastern N. America found the same pattern of bias that we report here in P. parviflora with the S-morph dominating in most populations and the L-morph occurring least frequently $(\mathrm{L}-\mathrm{morph}=0.25, \mathrm{M}$-morph $=0.35, \mathrm{~S}$-morph $=0.40, n=69$ 
populations; Barrett et al. 1983). Significantly, analysis of pollen production revealed a similar pattern, with mid-level anthers of the S-morph producing on average $74.2 \%$ more pollen than the corresponding anthers of the L-morph (Price and Barrett 1982). This pollen production difference also occurs in the closely related $P$. sagittata and a more limited morph-ratio survey is suggestive of a similar pattern of morph-ratio bias $\quad(\mathrm{L}-$ morph $=0.28, \quad \mathrm{M}$-morph $=0.36$, S-morph $=0.36, n=8$ populations; Glover and Barrett et al. 1983), although a larger survey involving more populations would clearly be required to confirm this. Significantly, the same pattern of pollen production as occurs in these Pontederia species is also evident in Eichhornia azurea, the only species of the related genus with trimorphic incompatibility (Cunha et al. 2014). Differential mid-level stamen pollen production may therefore be a general feature of species with trimorphic incompatibility in the Pontederiaceae.

These associations between morph-ratio bias and pollen production differences at mid-level anthers in $P$. parviflora suggest that mating asymmetries between the morphs could play an important role in causing the patterns we observed in the Pantanal. Specifically, because the S-morph produces roughly twice as much pollen at mid-level anthers than the L-morph it should be a better competitor in fertilizing ovules of the M-morph, the only ovules that mid-level pollen can fertilize under disassortative mating. This superiority in male function should increase its frequency in populations and concomitantly depress the frequency of the L-morph. Our deterministic and stochastic simulations of morph-frequency dynamics confirmed that this process could occur and both models returned equilibrium morph frequencies that were remarkably close to the average morph frequencies from our survey of 71 populations of $P$. parviflora (Table 2; Fig. 7). A similar result was also obtained in $P$. cordata when simulations using the observed pollen production differences matched closely the patterns of S-morph bias observed in natural populations (Barrett et al. 1983). The male mating asymmetry hypothesis could be tested by measuring the outcross siring success of the Land $\mathrm{S}$ morph using hypervariable genetic markers such as microsatellites (e.g., Hodgins and Barrett 2008), or single nucleotide polymorphisms.

An alternative hypothesis to explain the distinct pattern of morph-ratio bias that we observed in $P$. parviflora concerns the potential influence of self-compatibility on mating patterns. Although we did not explicitly determine through controlled pollinations whether $P$. parviflora is selfincompatible, it is highly likely that the species possesses a functioning trimorphic incompatibility system that enforces disassortative mating. Three lines of evidence support this assumption. First, to our knowledge there are no heterostylous species reported with significant pollen size heteromorphism that do not possess heteromorphic incompatibility (Dulberger 1992). Second, among the 5-6 species of Pontederia four have been examined experimentally and all possess trimorphic incompatibility and conspicuous pollen-size trimorphism similar to $P$. parviflora (Barrett 1977b; Glover and Barrett 1983; Barrett and Anderson 1985; Puentes et al. 2013). Finally, the maintenance of tristyly in the vast majority of $P$. parviflora populations would be unlikely without high levels of disassortative mating enforced by trimorphic incompatibility. Weak expression of trimorphic incompatibility in $P$. parviflora could potentially influence morph-ratio bias. However, this would require that the S-morph possess weak incompatibility, with higher selfing increasing its frequency in populations, assuming negligible inbreeding depression, which seems unlikely in a predominantly outcrossing species (Husband and Schemske 1996). But in common with other tristylous species (e.g., Lythrum salicaria - Balogh and Barrett 2018), including the four Pontederia species that have been studied experimentally, the M-morph possesses the weakest incompatibility and the S-morph has the strongest self-incompatibility system. Thus, it is not likely that the specific pattern of morph-ratio bias in P. parviflora that we report is the consequence of morph-specific differences in selfing rate because of the weak expression of trimorphic incompatibility.

\section{A developmental hypothesis for differential male fertility}

In tristylous species pollen production generally varies with anther height; short-level stamens produce the most pollen and long-level stamens the least (e.g., Cunha et al. 2014; Costa et al. 2017; Weller 1976a, 1976b). But stamens located at the same level usually produce equivalent quantities of pollen, as we found for long- and short-level stamens of $P$. parviflora. Pollen production equivalence of corresponding stamen levels should result in symmetrical disassortative mating. In populations, each morph on average mates equally with the other two compatible mating partners and this results in isoplethy (see Fig 13.1b; Barrett and Hodgins 2006). In Pontederia this pattern of mating may not occur because mid-level anthers of the S-morph produce approximately twice as much pollen on average as mid-level anthers of the L-morph (Fig. 1).

What might be the proximate mechanism(s) causing this difference in male gametic output in $P$. parviflora and related species? The answer may lie in differences in development among stamen levels in tristylous Pontederiaceae (Richards and Barrett 1987, 1992). In this family, long- and short-level stamens have identical insertions patterns on the inner and outer tepals comprising the perianth tube. But in contrast, the arrangement for mid-level 
stamens differs as an inevitable consequence of the structural architecture of tristyly. In the S-morph, mid-level stamens are the lower set and their filaments are therefore inserted on the dorsal (upper) surface of the floral tube whereas in the L-morph they are upper set of stamens and are inserted on the ventral (lower) surface (see Fig. 4 in Richards and Barrett 1987). These developmental contrasts are associated with an anther size dimorphism; mid-level anthers of the S-morph are significantly larger than the corresponding anthers of the L-morph and this probably explains their greater pollen production (Price and Barrett 1982)

Small differences in the timing of growth and onset of microsporogenesis between the two mid-level stamens may cause the observed differences in pollen production of Pontederia species and Eichhornia azurea. For example, in the related tristylous Eichhornia paniculata, premeiotic differences in the number and size of pollen mother cells and the time of entry into meiosis between anther levels are evident (Richards and Barrett 1984). Histological investigation of these events in mid-level stamens of Pontederia species would be valuable to test the proposed developmental hypothesis.

Fundamental differences between monocotyledonous and dicotyledonous flowers in the organization of tristyly probably explains why in Lythraceae and Oxalidaceae there is no evidence of pollen production differences at mid-level stamens (see Table 1 in Richard and Barrett 1992). The perianth in Pontederiaceae is composed of two series and within-flower stamen dimorphism is organized dorsiventrally and thus has a fundamentally different architecture compared to tristylous taxa of Lythraceae and Oxalidaceae, which possess radial organization of stamens. Because in the two dicotyledonous families the calyx is morphologically distinct from the corolla, each stamen level within a flower is associated with a different perianth series. In contrast, within-flower stamen dimorphism in Pontederiaceae is not correlated with tepal series and all stamen levels include stamens from both series. For mid-level anthers this results in developmentally heterogeneous insertion patterns which likely influence the timing of stamen development (Richard and Barrett 1992). Thus, according to this hypothesis differences in male fertility between the L- and S-morph and the resulting biased morph ratios may be a simple non-adaptive consequence of a developmental constraint associated with the architecture of tristyly in Pontederiaceae.

Our investigations of $P$. parviflora have revealed that populations in the Pantanal wetlands of Brazil are predominantly tristylous. Most aspects of the reproductive system of populations we investigated conform to those that typically characterize tristylous species in other families. These include the reciprocal positioning of sex organs, equivalent flower size and female fertility among morphs, and conspicuous pollen-size trimorphism and pollen production differences among stamen levels. However, an earlier report of a few isolated populations of $P$. parviflora in Panama stated that populations in this region were exclusively comprised of a single monomorphic homostylous morph (Lowden 1973). Derived homostylous populations are reported in the majority of heterostylous families, including Pontederiaceae, and are commonly self-compatible and often highly selfing (Barrett et al. 1989). The disjunct geographical differentiation of reproductive systems in $P$. parviflora is consistent with Baker's law (Baker 1955) and suggests that presumably selfing homostyles of $P$. parviflora established in Central America following long-distance dispersal from lowland South America. This geographical pattern is commonly reported in other heterostylous species with extensive distributions in which floral polymorphism is replaced by monomorphism at range limits (reviewed in Barrett 1989).

In conclusion, male fertility variation is likely to occur in sexually monomorphic populations of other plant species. This can result from phenotypic variation among individuals in pollen production associated with the age, size and condition of individuals. In most cases, its recognition is likely to go undetected and it may not be readily apparent how much of the observed quantitative variation in male fertility has a heritable basis without detailed genetic analysis. Polymorphic sexual systems such as heterostyly therefore provide an unusual opportunity to investigate variation in male fertility. The floral morph ratios in a population provide a visible phenotypic signature of mating patterns in preceding generations and genetically-based differences among floral morphs in pollen production causing mating asymmetries are a potential cause of deviations from isoplethy.

\section{Data archiving}

Data available from the Dryad Digital Repository https:// doi.org/10.5061/dryad.7bj715s

Acknowledgements This research was supported by Special Visiting Researcher grant (88881.062191/2014-01) from Science Without Borders Program (CAPES and CNPq) and a Discovery Grant from the Natural Sciences and Engineering Research Council of Canada to S.C. H.B. A Special Visiting Researcher grant enabled S.C.H.B. to conduct fieldwork in the Pantanal and support a post-doctoral grant to N.L.C. (88887.067088/2014-00). We thank Milena Delatorre for assistance with field sampling, Martin Morgan for providing software used in our computer simulations, Erich Fischer for encouragement.

Author contributions NLC and SCHB planned the research and conducted the fieldwork, NLC analyzed the data and NLC and SCHB wrote the manuscript. 


\section{Compliance with ethical standards}

Conflict of interest The authors declare that they have no conflict of interest.

Publisher's note: Springer Nature remains neutral with regard to jurisdictional claims in published maps and institutional affiliations.

\section{References}

Ågren J, Ericson L (1996) Population structure and morph-specific fitness differences in tristylous Lythrum salicaria. Evolution 50:126-139

Baker HG (1955) Self-compatibility and establishment following "long-distance" dispersal. Evolution 9:347-349

Balogh CM, Barrett SCH (2016) Stochastic processes during invasion: the influence of population size on style-morph frequency variation in Lythrum salicaria (purple loosestrife). Int J Plant Sci 177:409-418

Balogh CM, Barrett SCH (2018) Genetic and environmental influences on partial self-incompatibility in Lythum salicaria (Lythaceae). Int J Plant Sci 179:423-425

Barrett SCH (1977a) Tristyly in Eichhornia crassipes (Mart.) Solms (Water Hyacinth). Biotropica 9:230-238

Barrett (1977b) The breeding system of Pontederia rotundifolia L., a tristylous species. New Phytol 78:209-220

Barrett SCH, Anderson JM (1985) Variation in expression of trimorphic incompatibility in Pontederia cordata L. (Pontederiaceae). Theor Appl Genet 70:355-362

Barrett SCH (1989) The evolutionary breakdown of heterostyly. In: Bock JH, Linhart YB eds. The Evolutionary Ecology of Plants. Westview press, Boulder, USA, p 151-169

Barrett SCH, Harder LD, Cole WW (2004) Correlated evolution of floral morphology and mating-type frequencies in a sexually polymorphic plant. Evolution 58:964-975

Barrett SCH, Hodgins KA (2006) Floral design and the evolution of asymmetrical mating systems. In: Harder LD, Barrett SCH eds. Ecology and Evolution of Flowers. Oxford University Press, Oxford, UK, p 239-255

Barrett SCH, Morgan MT, Husband BC (1989) The dissolution of a complex polymorphism: the evolution of self-fertilization in tristylous Eichhornia paniculata (Pontederiaceae). Evolution 43:1398-1416

Barrett SCH, Price SD, Shore JS (1983) Male fertility and anisoplethic population structure in tristylous Pontederia cordata (Pontederiaceae). Evolution 37:745-759

Barrett SCH (1993) The evolutionary biology of tristyly. In: Futuyma D, Antonovics J (eds) Oxford Surveys in Evolutionary Biology 9. Oxford University Press, Oxford, UK, p 283-326

Bates D, Maechler M, Bolker B, Walker S (2015) Fitting linear mixedeffects models using lme4. J Stat Soft 67:1-48

Charlesworth D (1979) The evolution and breakdown of tristyly. Evolution 33:486-498

Clarke BC, Partridge L, Robertson A (1988) Frequency-Dependent Selection. Cambridge University Press, New York, NY

Costa J, Castro S, Loureiro J, Barrett SCH (2017) Experimental insights on Darwin's cross-promotion hypothesis in tristylous purple loosestrife (Lythrum salicaria). Am J Bot 104:616-626

Cunha NL, Fischer E, Lorenz-Lemke AP, Barrett SCH (2014) Floral variation and environmental heterogeneity in a tristylous clonal aquatic of the Pantanal wetlands of Brazil. Ann Bot 114:1637-1649

Darwin C (1877) The Different Form of Flowers on Plants of the Same Species. John Murray, London, UK
Dulberger R (1992) Floral polymorphisms and their functional significance in the heterostylous syndrome. In: Barrett SCH ed. Evolution and Function of Heterostyly. Springer-Verlag, Berlin, $p$ $41-84$

Eckert CG, Barrett SCH (1992) Stochastic loss of style morphs from populations of tristylous Lythrum salicaria and Decodon verticillatus. Evolution 46:1014-1029

Eckert CG, Barrett SCH (1993) The inheritance of tristyly in Decodon verticillatus (Lythraceae). Heredity 71:473-480

Eckert CG, Barrett SCH (1995) Style morph ratios in tristylous Decodon verticillatus (Lythraceae): selection vs. historical contingency. Ecology 76:1051-1066

Eckert CG, Manicacci D, Barrett SCH (1996) Frequency-dependent selection on morph ratios in tristylous Lythrum salicaria (Lythraceae). Heredity 77:581-588

Ferrero V, Barrett SCH, Castro S, Caldeirinha P, Navarro L, Loureiro J, Rodríguez-Echeverría (2015) Invasion genetics of the Bermuda buttercup (Oxalis pes-caprae): complex intercontinental patterns of genetic diversity, polyploidy and heterostyly characterize both native and introduced ranges. Mol Ecol 24:2143-2155

Fisher RA (1941) The theoretical consequences of polyploid inheritance for the mid style form of Lythrum salicaria. Ann Eugen 11:31-38

Fisher RA, Mather K (1943) The inheritance of style length in Lythrum salicaria. Ann Eugen 12:1-23

Gettys LA, Wofford DS (2008) Genetic control of floral morph in tristylous Pickerelweed (Pontederia cordata L.). J Hered 99:558-563

Glover DE, Barrett SCH (1983) Trimorphic incompatibility in Mexican populations of Pontederia sagittata Presl. (Pontederiaceae). New Phytol 95:439-455

Heuch I, Lie RT (1985) Genotype frequencies associated with incompatibility systems in tristylous plants. Theor Popul Biol 27:318-336

Heuch I (1979a) Equilibrium populations of heterostylous plants. Theor Popul Biol 15:43-57

Heuch I (1979b) The effect of partial self-fertilization on type frequencies in heterostylous plants. Ann Bot 44:611-616

Heuch I (1980) Loss of incompatibility types in finite populations of the heterostylous plant Lythrum salicaria. Hereditas 92:53-57

Hodgins KA, Barrett SCH (2008) Asymmetrical mating patterns and the evolution of biased style-morph ratios in a tristylous daffodil. Genet Res 90:3-15

Hothorn T, Bretz F, Westfall P (2008) Simultaneous inference in general parametric models. Biom J 50:346-363

Husband BC, Barrett SCH (1992) Genetic drift and the maintenance of the style length polymorphism in tristylous populations of Eichhornia paniculata (Pontederiaceae). Heredity 69:440-449

Husband BC, Schemske DW (1996) Evolution of the magnitude and timing of inbreeding depression in plants. Evolution 50:54-70

Lewis D, Jones DA (1992) The genetics of heterostyly. In: Barrett $\mathrm{SCH}$ ed. Evolution and Function of heterostyly. Springer-Verlag, Berlin, p 129-150

Lloyd DG, Webb CJ (1992) The evolution of heterostyly. In: Barrett $\mathrm{SCH}$ ed. Evolution and Function of heterostyly. Springer-Verlag, Berlin, p 151-178

Lowden RM (1973) Revision of the genus Pontederia. Rhodora $75: 426-487$

McCauley DE, Brock MT (1998) Frequency-dependent fitness in Silene vulgaris, a gynodioecious plant. Evolution 52:30-36

Meyer D, Zeileis A, Hornik K (2016) vcd: Visualizing Categorical Data. $\mathrm{R}$ package version 1.4-3.

Morgan M (2016) Tristyly: Stochastic Simulation of Tristylous Genetic Polymorphisms. R package version 0.0.1. 
Morgan MT, Barrett SCH (1988) Historical factors and anisoplethic population structure in tristylous Pontederia cordata: a reassessment. Evolution 42:496-504

Ornduff R (1966) The breeding system of Pontederia cordata L. Bull Torre Bot Club 93:407-416

Pott VJ, Pott A (2000) Plantas Aquáticas do Pantanal. Embrapa, Brasília

Puentes A, Cole WW, Barrett SCH (2013) Trimorphic incompatibility in Pontederia subovata (Pontederiaceae): An aquatic macrophyte from lowland South America. Int J Plant Sci 174:47-56

Price SD, Barrett SCH (1982) Tristyly in Pontederia cordata L. (Pontederiaceae). Can J Bot 60:897-905

Richards JH, Barrett SCH (1984) The developmental basis of tristyly in Eichhornia paniculata (Pontederiaceae). Am J Bot $71: 1347-1363$

R Core Team (2017) R: A language and environment for statistical computing. R Foundation for Statistical Computing, Vienna, Austria. https://www.R-project.org/

Richards JH, Barrett SCH (1987) Development of tristyly in Pontederia cordata (Pontederiaceae). I Mature floral structure and patterns of relative growth of reproductive organs. Am J Bot 74:1831-1841

Richards JH, Barrett SCH (1992) The development of heterostyly. In: Barrett SCH ed. Evolution and Function of Heterostyly. SpringerVerlag, Berlin, p 85-127
Sarkar D (2008) Lattice: Multivariate Data Visualization with R. Springer, New York, NY

Sokal RR, Rohlf FJ (2011) Biometry, 4th edn. W. H. Freeman, New York, NY

Vallejo-Marín M, Dorken ME, Barrett SCH (2010) The ecological and evolutionary consequences of clonality for plant mating. Annu Rev Ecol Evol Syst 41:193-213

Weber JF, Weller SG, Sakai AK, Nguyen L-Q, Khuu D (2013a) Breeding system evolution in Oxalis alpina: asymmetrical expression of tristylous incompatibility. Int $\mathbf{J}$ Plant Sci 174:179-188

Weber JF, Weller SG, Sakai AK, Tsyusko OV, Glenn TC, Domínguez CA, Molina-Freaner FE, Fornoni J, Tran M, Nguyen N, Nguyen K, Tran L-K, Joice G, Harding E (2013b) The role of inbreeding depression and mating system in the evolution of heterostyly. Evolution 67:2309-2322

Weller SG (1976a) The genetic control of tristyly in Oxalis section Ionoxalis. Heredity 37:387-393

Weller SG (1976b) Breeding system polymorphism in a heterostylous species. Evolution 30:442-454

Wickham H (2007) Reshaping data with the reshape package. J Stat Softw 21:1-20

Wickham H (2009) ggplot2: Elegant Graphics for Data Analysis. 3rd printing, 2010 edn. Springer, New York, NY 